Supplementary Information for

\title{
Amphiphilic Perfluoropolyether Copolymers for Effective Removal of PFAS from Aqueous Environments
}

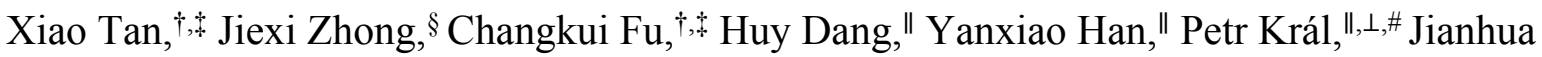
Guo, ${ }^{\S}$ Zhiguo Yuan, ${ }^{\S}$ Hui Peng, ${ }^{\dagger, \star}$ Cheng Zhang, ${ }^{* \dagger, \$}$ and Andrew K. Whittaker* ${ }^{\dagger, \star}$

${ }^{\dagger}$ Australian Institute for Bioengineering and Nanotechnology, The University of Queensland, Brisbane, QLD 4072, Australia

+ ARC Centre of Excellence in Convergent Bio-Nano Science and Technology, The University of Queensland, Brisbane, QLD 4072, Australia

$\S$ Advanced Water Management Centre, The University of Queensland, Brisbane, QLD, 4072, Australia

" Department of Chemistry and $\perp^{\perp}$ Department of Physics, University of Illinois at Chicago, Chicago, Illinois 60607, United States

\# Department of Biopharmaceutical Sciences, University of Illinois at Chicago, Chicago, Illinois 60612, United States 
(b)

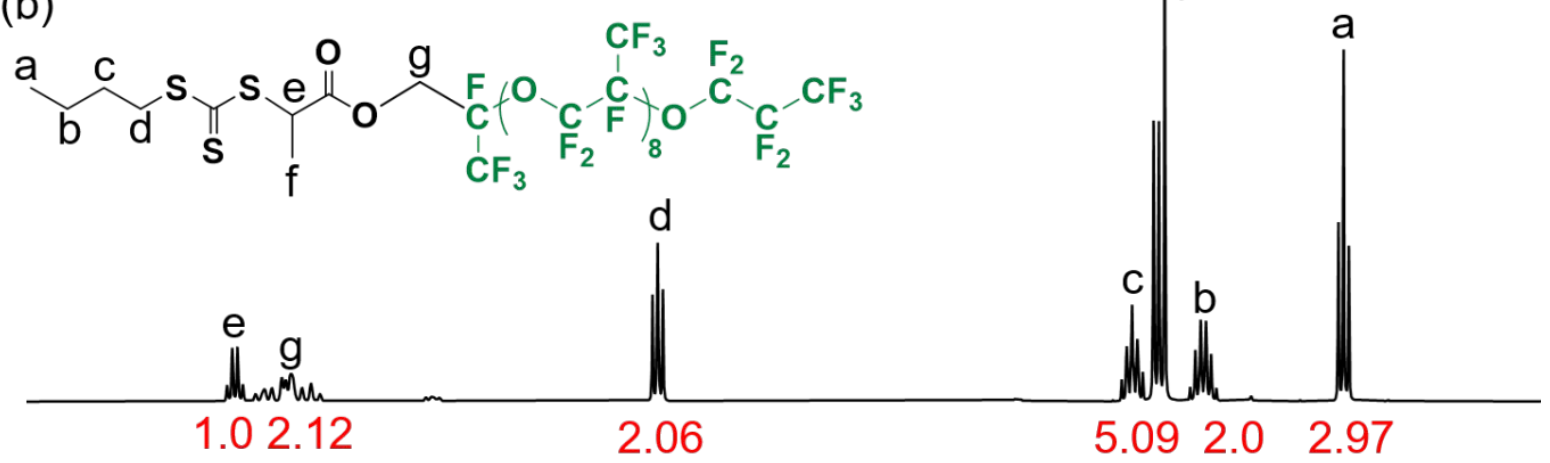

(a)<smiles>[B]CC(=S)SC(=S)OC(O)C(=O)O</smiles>
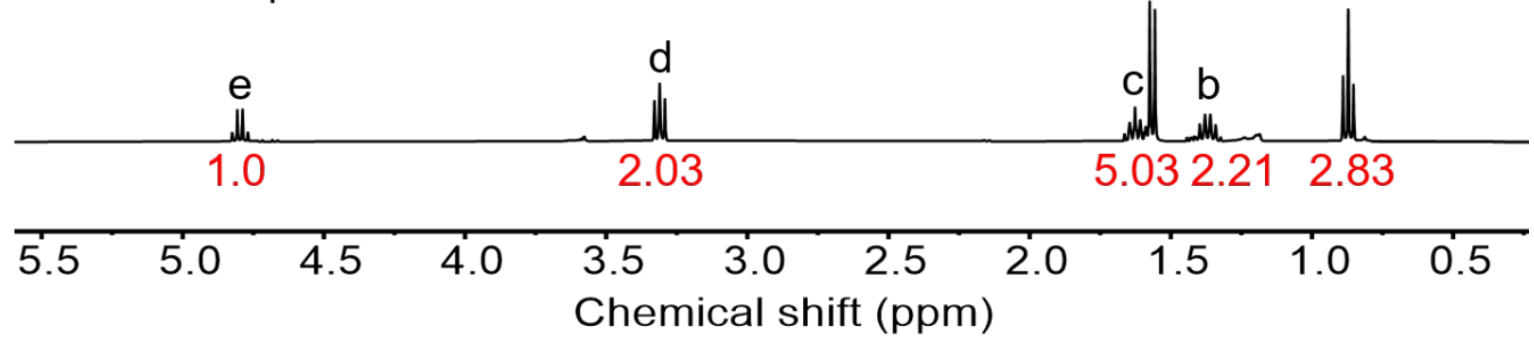

Figure S1. ${ }^{1} \mathrm{H}$ NMR spectra of 2-(butylthiocarbonothioylthio)-propionic acid (BTPA) (a) and BTPA-perfluoropolyether (PFPE) macro-RAFT agent (b) in $\mathrm{CDCl}_{3}$. 


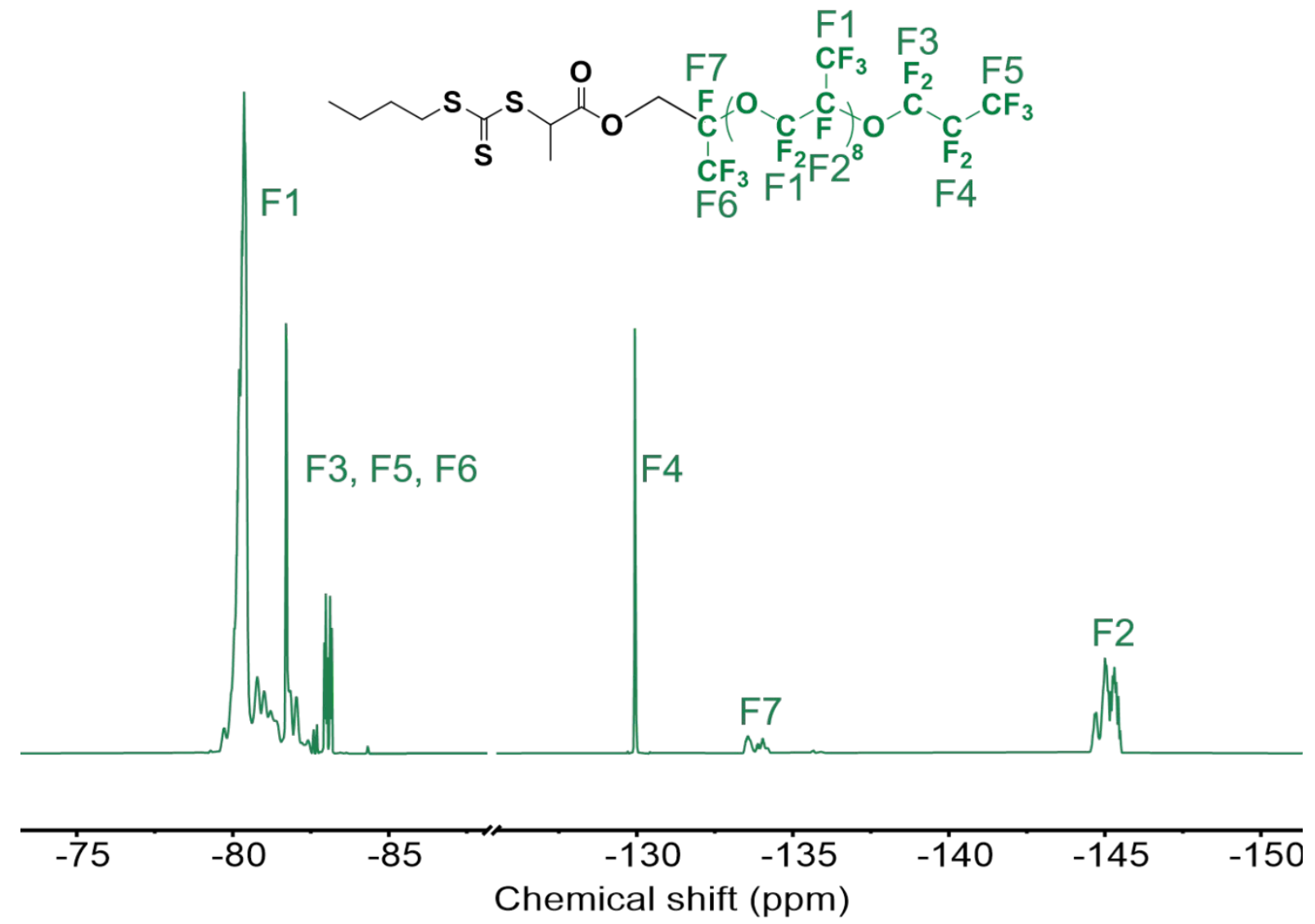

Figure S2. ${ }^{19} \mathrm{~F}$ NMR spectrum of BTPA-PFPE macro-RAFT agent in $\mathrm{CDCl}_{3}$. 


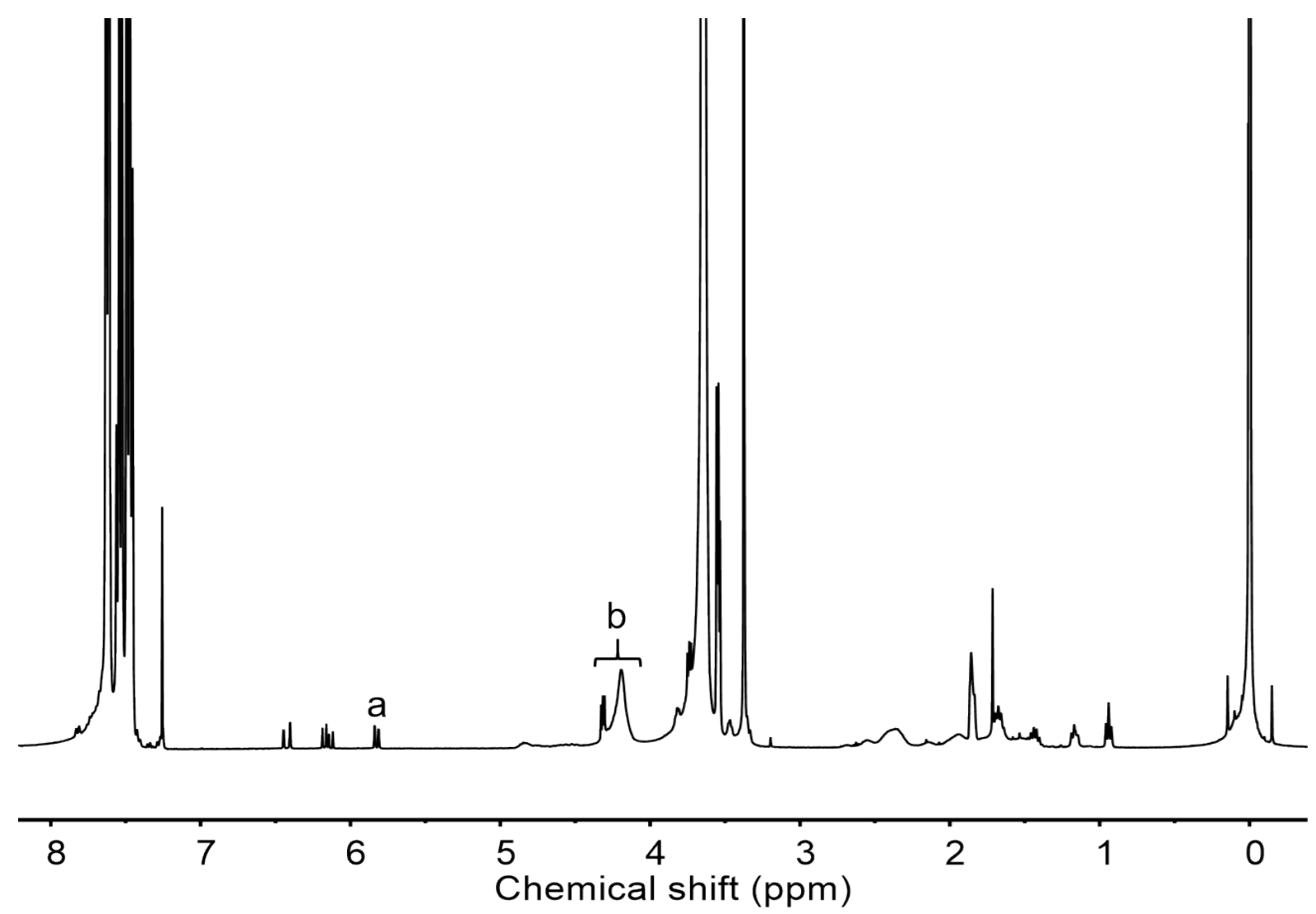

Figure S3. ${ }^{1} \mathrm{H}$ NMR spectrum of crude P5 mixtures. a, unreacted monomer peak $\left(1 \mathrm{H}, \mathrm{CH}_{2}=\right)$; b, unreacted monomer $(2 \mathrm{H}, \mathrm{CH} 2 \mathrm{O}-)+$ polymer peak $(2 \mathrm{H}, \mathrm{CH} 2 \mathrm{O}-)$. Conversion $(\%)=($ $\left.\int b-2 \int a\right) / \int b \times 100$. 


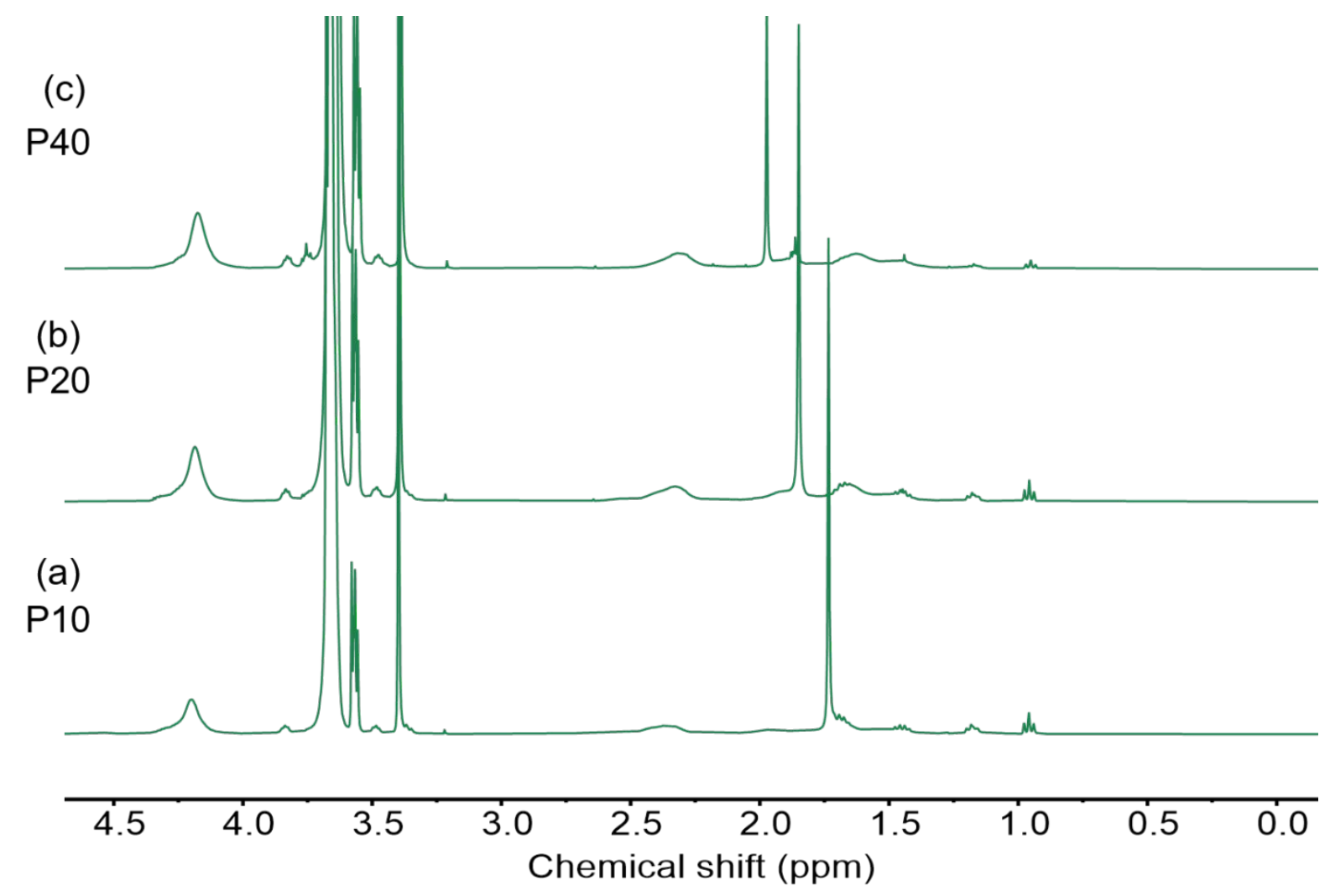

Figure S4. ${ }^{1} \mathrm{H}$ NMR spectra of purified P10, P20 and P40 in $\mathrm{CDCl}_{3}$. (a) P10; (b) P20 and (c) P40. 
Table S1. Intensity-based hydrodynamic diameters of poly(OEGA) $-\mathrm{PFPE}$ block copolymers with or without presence of PFOA in PBS. Polymers, $20 \mathrm{mg} / \mathrm{mL}$, determined by DLS.

\begin{tabular}{|c|c|c|c|c|c|c|c|c|}
\hline & \multicolumn{7}{|c|}{$D_{\mathrm{h}}(\mathrm{nm}$, intensity-based } \\
\hline $\begin{array}{c}{[\text { PFOA }]} \\
(\mathrm{mM})\end{array}$ & P5 & PDI & P10 & PDI & P20 & PDI & P40 & PDI \\
\hline 0 & 10.94 & 0.07 & 10.28 & 0.15 & 11.3 & 0.07 & 15.77 & 0.14 \\
\hline 0.8 & 10.61 & 0.11 & 10.03 & 0.16 & 11.28 & 0.07 & 15.72 & 0.14 \\
\hline 1.6 & 10.27 & 0.11 & 9.47 & 0.19 & 11.16 & 0.07 & 15.02 & 0.16 \\
\hline 3.2 & 9.73 & 0.14 & 9.38 & 0.19 & 11.08 & 0.1 & 14.03 & 0.2 \\
\hline 6.4 & 9.16 & 0.17 & 8.53 & 0.19 & 10.29 & 0.11 & 12.62 & 0.21 \\
\hline
\end{tabular}


(d)

P40+3.2 mM PFOA

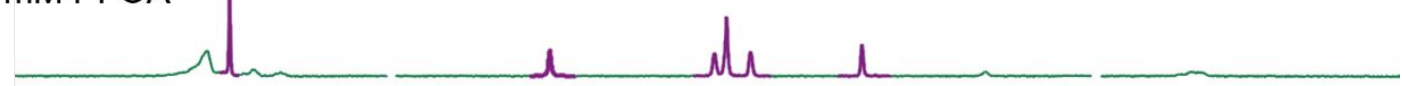

(c)

P20+3.2 mM PFOA

Nh

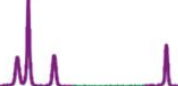

(b)

P10+3.2 mM PFOA
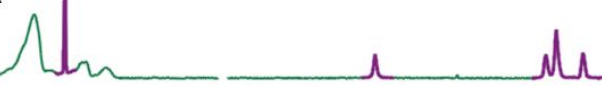

(a)

$3.2 \mathrm{mM}$ PFOA

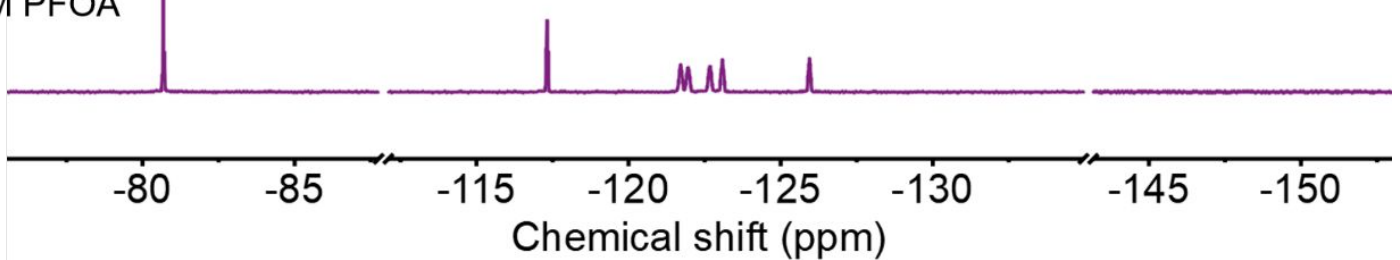

Figure S5. ${ }^{19} \mathrm{~F}$ NMR spectra of PFOA with and without the presence of P10, P20 and P40 (90\% PBS $+10 \% \mathrm{D}_{2} \mathrm{O}$ ). (a) PFOA only; (b) PFOA in the presence of P10; (c) PFOA in the presence of P20 and (d) PFOA in the presence of P40. PFOA, $3.2 \mathrm{mM}$; polymers, $20 \mathrm{mg} / \mathrm{mL}$. 
(a)

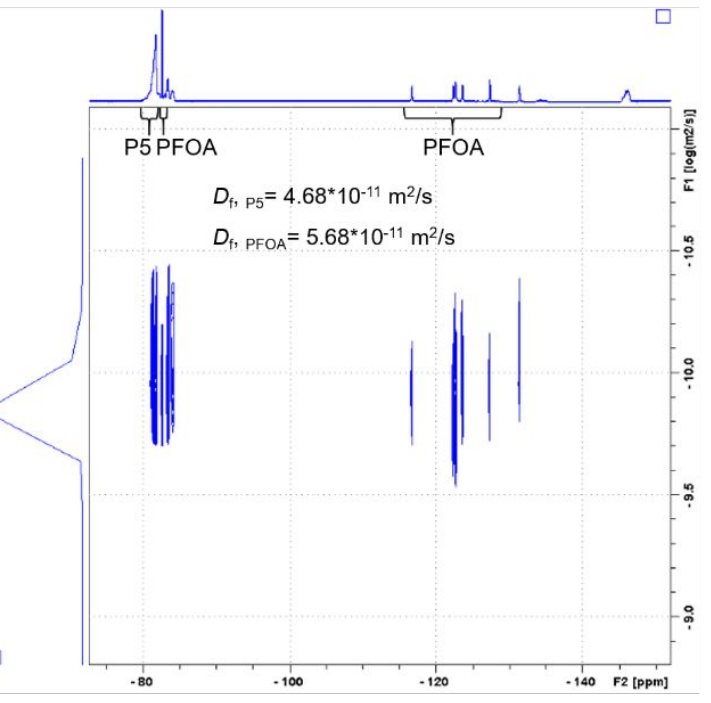

(c)

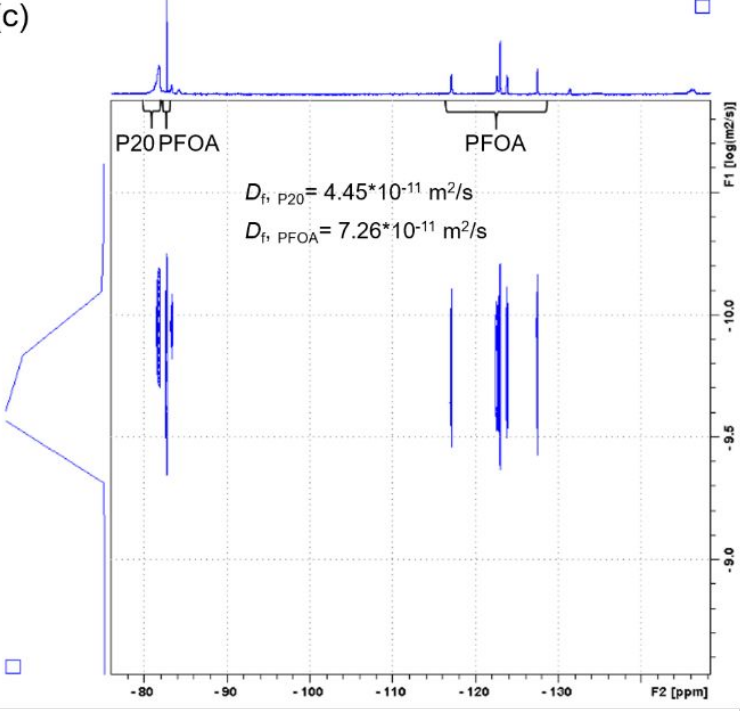

(b)

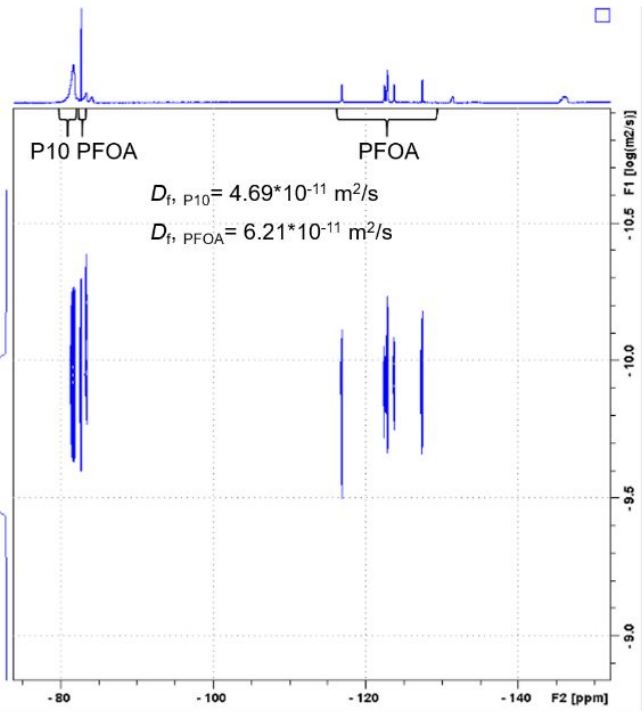

(d)

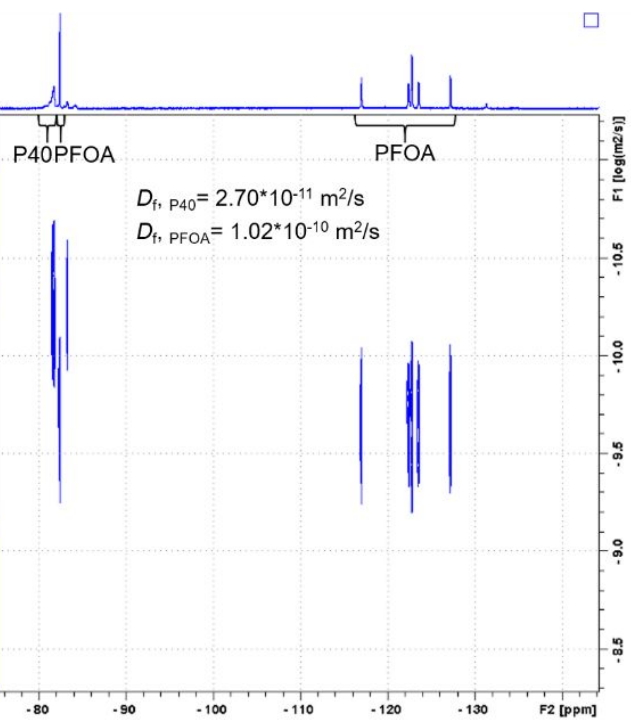

Figure S6. ${ }^{19}$ F DOSY NMR spectra of $3.2 \mathrm{mM}$ PFOA in the presence of $20 \mathrm{mg} / \mathrm{mL}$ of PFPEbased polymers $\left(90 \% \mathrm{PBS}+10 \% \mathrm{D}_{2} \mathrm{O}\right)$ at room temperature. (a) P5+PFOA, (b) P10+PFOA, (c) P20+PFOA and (d) P40+PFOA. 
Table S2. Peak width at half height (in $\mathrm{Hz}$ ) of PFOA peaks $\mathrm{F}(1)-\mathrm{F}(7)$ with and without the presence of PFPE block copolymers (P5-P40) in PBS.

\begin{tabular}{|c|c|c|c|c|c|c|}
\hline & $F(1) \mathrm{Hz}$ & $\mathrm{F}(7) \mathrm{Hz}$ & \multicolumn{3}{|c|}{$\mathrm{F}(3-6) \mathrm{Hz}$ from left to right in } & $\mathrm{F}(2) \mathrm{Hz}$ \\
& & & \multicolumn{3}{|c|}{ spectra } \\
\hline P40+PFOA & 22.8 & 35.6 & 49.6 & 37.5 & 46.4 & 35.9 \\
\hline P20+PFOA & 14.6 & 37.9 & 50.0 & 28.7 & 46.9 & 33.6 \\
\hline P10+PFOA & 14.3 & 39.6 & 50.7 & 50.6 & 47.8 & 36.2 \\
\hline P5+PFOA & 25.1 & 49.4 & 57.0 & $95.3 *$ & 51.0 & 39.7 \\
\hline PFOA only & 12.6 & 15.4 & 39.8 & 42.7 & 41.8 & 38.1 \\
\hline
\end{tabular}

* Split into two peaks 

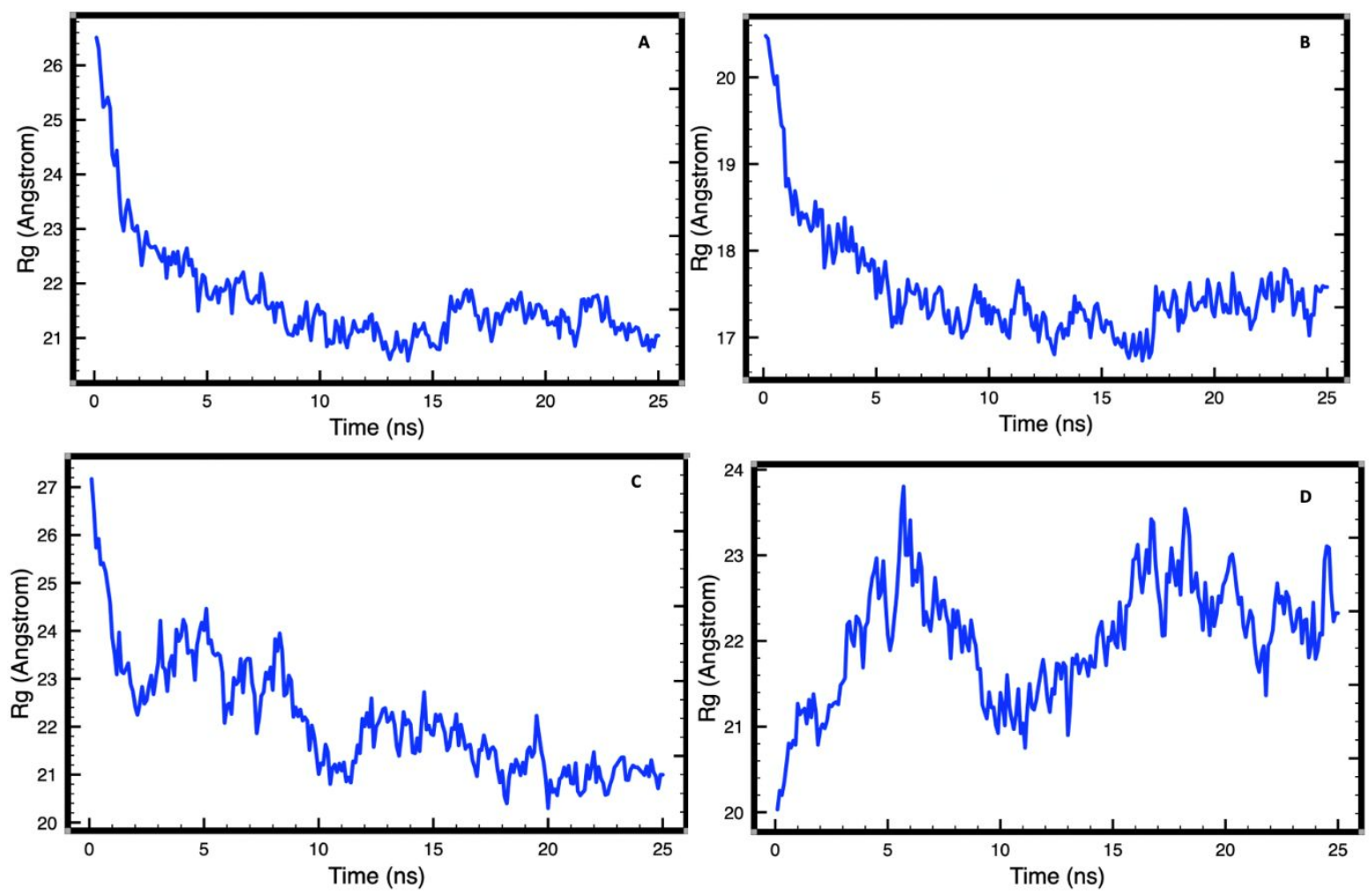

Figure S7. Radius of gyration $(\mathrm{Rg})$ of aggregated polymers (polymers only determined by MD simulations). A, P5; B, P10; C, P20; D, P40. 
Table S3. ${ }^{19} \mathrm{~F}$ NMR peak width at half height (in $\mathrm{Hz}$ ) of P5 peak F1 with different concentrations of PFOA in PBS.

\begin{tabular}{|c|c|}
\hline$[$ PFOA $](\mathrm{mM})$ & $\mathrm{F} 1 \mathrm{~Hz}$ \\
\hline $0 \mathrm{mM}$ & 252.8 \\
\hline $0.8 \mathrm{mM}$ & 241.9 \\
\hline $1.6 \mathrm{mM}$ & 188.3 \\
\hline $3.2 \mathrm{mM}$ & 164.9 \\
\hline $6.4 \mathrm{mM}$ & 142.9 \\
\hline
\end{tabular}


(b)

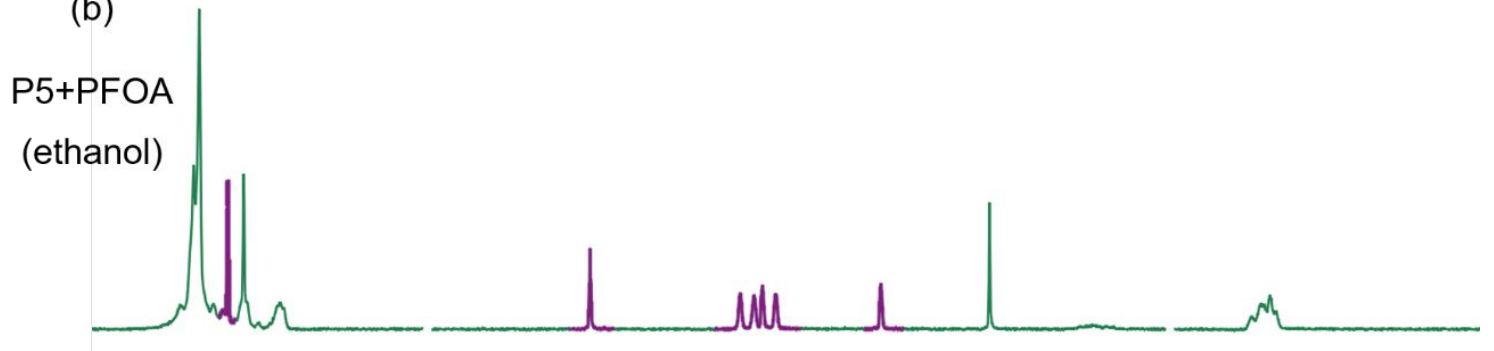

(a)

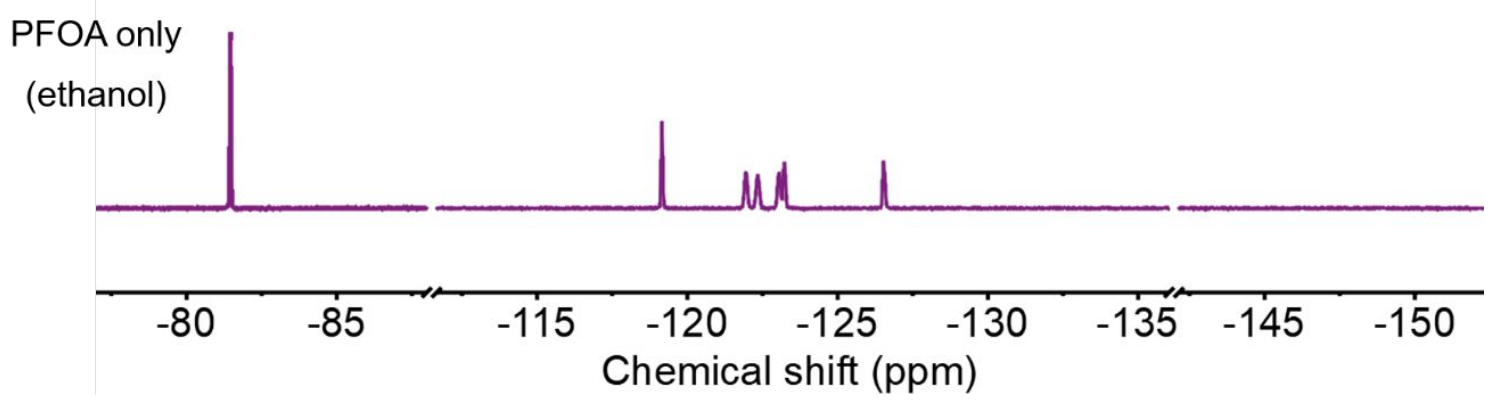

Figure S8. ${ }^{19}$ F NMR spectra of PFOA with and without the presence of P5 (in ethanol with a coaxial insert tube containing $\mathrm{D}_{2} \mathrm{O}$ ). (a) PFOA only; (b) PFOA in the presence of P5. PFOA, $3.2 \mathrm{mM}$; polymers, $20 \mathrm{mg} / \mathrm{mL}$. 


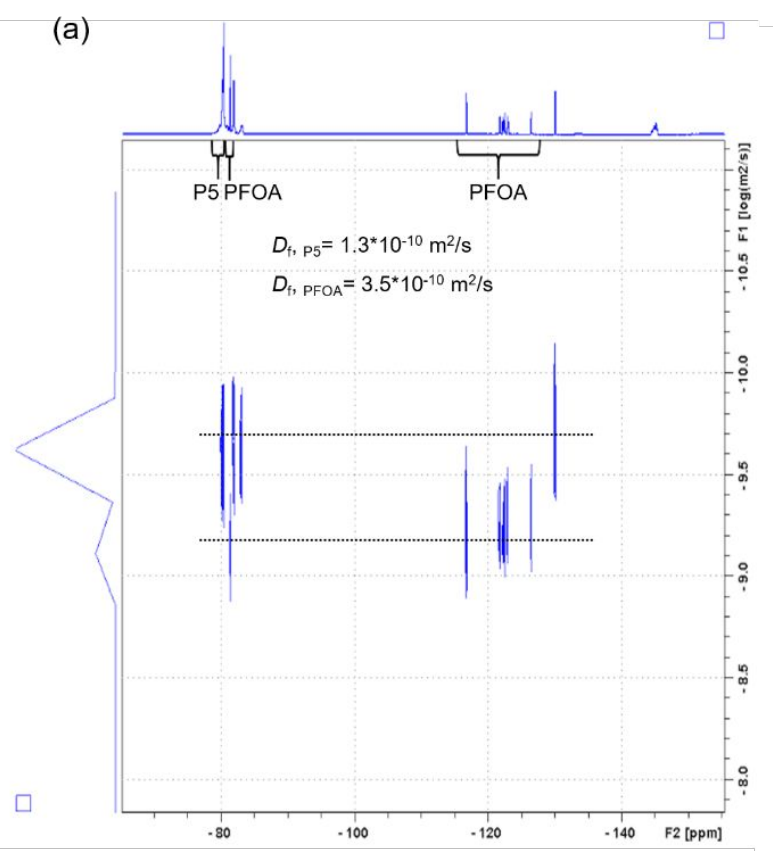

(b)

Figure S9. ${ }^{19} \mathrm{~F}$ DOSY NMR for PFOA release and re-adsorption. (a) ${ }^{19} \mathrm{~F}$ NMR DOSY of P5+PFOA after addition of ethanol for desorption. (b) ${ }^{19} \mathrm{~F}$ NMR DOSY of P5+PFOA after evaporating ethanol and addition of deionized water for re-adsorption. P5, $20 \mathrm{mg} / \mathrm{Ml}$; PFOA, $3.2 \mathrm{mM}$. 